\title{
DAMPAK PERKEBUNAN KELAPA SAWIT RAKYAT TERHADAP PENDAPATAN WILAYAH DESA (PDRB) DI PROVINSI JAMBI
}

\section{SMALLHOLDERS OIL PALM ESTATE IMPACT AGAINST VILLAGE GROSS REGIONAL DOMESTIC PRODUCT (GRDP) IN JAMBI PROVINCE}

\author{
Armen Mara ${ }^{1)}$ dan Yanuar Fitri) \\ 1) Program Studi Agrobisnis Fakultas Pertanian Universtas Jambi \\ armen_maraa@yahoo.co.id
}

\begin{abstract}
Smallholder oil palm estate in Jambi Province is growing. Some indicators are land development, production, and employment. Smallholder oil palm estate can be a major driver of the economy so that the country can move other economic sectors, such as trade, transport, electricity and gas, manufacture small industrial and other sectors, which in turn increases the income of the village as a whole. This study aimed to determine (1) the development of oil palm estate seen from land, production, and employment in the province of Jambi (2) Impact of smallholder oil palm estate against Gross Regional Domestic Product Villages in Jambi Province. The research method used in this study is a survey method. This method of research was done deductively, by conducting an analysis of the object. Data were collected from primary sources and secondary sources. The development of oil palm plantations quantitatively analyzed descriptively. To determine whether the development of oil palm plantations had such an impact is determined by the formula LQ (Location Quotient) and the magnitude of the impact made by Formula ME (multiplier effect). To determine the value of $L Q$ and $M E$ the sample villages can be determined that a major driver of the sector (Prime mover sector) in the village economy. These results indicate that oil palm plantations have grown rapidly both views of land, production, and employment. Oil palm plantations have an impact on the income of the people of the village, where 9 of 20 samples villages have values $L Q>1$ with the average $M E$ value was 1.4107 , which means that any increase in palm oil revenue amounted toRp1, -it will be able to increase the income of the region village as a whole amounted to1.4107times. The impact is especially true of the sub-sectors of trade, transport sub-sector, and electricity and gas sub-sector. The impact is small relative to the manufacturing sector.
\end{abstract}

Key words: smallholders oil palm estate, GRDB of villages, LQ, and ME. 


\section{PENDAHULUAN}

Perkebunanan kelapa sawit di Provinsi Jambi sejak beberapa tahun belakangan berkembang dengan pesat, terutama dilihat dari perkembangan luas lahan, produksi, jumlah tenaga kerja dan nilai ekspor. Perkembangan luas lahan kebun kelapa sawit tersebut bahkan lebih cepat dari perkembangan luas kebun karet yang merupakan tanaman tradisional rakyat dan telah berusia seratus tahun lebih. Diperkirakan pada masa mendatang luas kebun kelapa sawit tersebut akan melebihi luas kebun karet.

Perkembangan luas perkebunan kelapa sawit diperkirakan berdampak terhadap pendapatan masyarakat desa, terutama karena pemanfaatan lahan untuk kebun kelapa sawit pada umumnya lebih intensif dari pengusahaan tanaman lain dan adanya peningkatan harga kelapa sawit sejak beberapa tahun sebelumnya. Disamping itu, perkembangan luas tanaman kelapa sawit di Provinsi Jambi juga berperan dalam menyerap tenaga kerja, dimana pada tahun 2001 perkebunan kelapa sawit hanya menyerap tenaga kerja sebesar 108.676 orang sedangkan pada tahun 2007 penyerapan tenaga kerja meningkat menjadi 161.604 orang (Dinas Perkebunan Provinsi Jambi, 2008).

Perkembangan luas kebun kelapa sawit yang semula dimotori oleh perkebunan besar tersebut diikuti dengan pembangunan kebun kelapa sawit dengan pola swadaya. Perkembangan luas kebun kelapa sawit rakyat ini berpotensi dalam meningkatkan pendapatan wilayah desa yang terjadi melalui dampak perkebunan kelapa sawit terhadap sektor dan subsektor lainya, seperti sektor perdagangan. transportasi, dan industri pengolahan.

Pendapatan wilayah dapat dihitung dengan beberapa pendekatan produksi, yaitu jumlah nilai tambah produksi dari barang-barang dan jasa-jasa selama satu priode tertentu, misalnya satu tahun kalender (Ace Partadireja, 1983). Untuk keperluan ini perekonomian biasanya dibagi kedalam 11 sektor. Masing-masing sektor dibagi lagi kedalam beberapa sub sektor. Sektor pertanian dibagi kedalam sub sektor tanaman pangan, sub sektor perkebunan, sub sektor peternakan, sub sektor perikanan, dan sub sektor kehutanan. Demikian juga untuk sektor lainnya dibagi menjadi beberapa sub sektor sesuai dengan banyak cabang usaha pada sektor tersebut.

Penelitian tentang peranan perkebunan kelapa sawit terhadap perekonomian regional Provinsi Jambi sudah banyak dilakukan, terutama yang menggunakan metode LQ dan ME. Misalnya, Anggiat Heriyanto (2009) menjelaskan bahwa komoditi kelapa sawit merupakan sektor basis di Provinsi Jambi, baik dengan menggunakan harga konstan tahun 2003 maupun harga berlaku. Rozaina Ningsih dkk (2011) menemukan bahwa pemekaran wilayah memiliki dampak nyata terhadap pertumbuhan ekonomi wilayah. Namun, pertumbuhan ekonomi tersebut lebih disebabkan oleh pertambahan tenaga kerja yang setelah pemekaran tahun 2002 bertambah melalui migrasi yang 
tidak terkait dengan kebijakan pemekaran wilayah. Menurut Wayan R, Susila, dan IDM Darma Setiawan (2007) industri berbasis perkebunan mampu mendorong pertumbuhan ekonomi, penciptaan lapangan kerja dan pendapatan, serta perbaikan distribusi pendapatan.

Pembangunan pedesaan menurut Ropingi dan Sudartono (2008) harus mencakup multi sektor, terutama pengembangan industri rumah tangga dan perdagangan. Bahwa pengembangan industri rumah tangga dan perdagangan di Kecamatan Gunung Kidul dapat menyerap tenaga kerja dari sektor pertanian dan sekaligus mengurangi beban sektor pertanian. Mariati (2012) menjelaskan bahwa produksi nasional, konsumsi dunia, dan harga dunia secara bersama-sama berpengaruh nyata terhadap ekspor CPO di Indonesia. Namun secara parsial hanya variabel produksi nasional dan harga dunia yang berpengaruh secara nyata terhadap ekspor CPO di Indonesia.

Menurut teori ekonomi regional, perekonomian dapat dibagi menjadi 2 (dua) bagian, yaitu sektor basis (export base) dan sektor non basis (non export base). Untuk sektor basis dalam perekonomian regional tersebut dapat digunakan metode Location Quotient (LQ). Dimana bila nilai LQ $>1$ maka sektor tersebut dianggap sebagai sektor basis dan sebaliknya jika nilai LQ $\leq 1$ sektor tersebut dianggap sektor non basis. Untuk menentukan nilai LQ maka digunakan rumus berikut (Isard dkk, 1998):

$$
L Q=\frac{E_{j}^{i} / E_{j}}{E^{i} / E}
$$

dimana $\mathrm{LQ}=$ Location Quotient, $E_{j}^{i}=$ Tenaga kerja dalam aktivitas i dalam region $\mathrm{j}, E_{j}=$ Total tenaga kerja dalam region $\mathrm{j}, E^{i}=$ Tenaga kerja dalam aktivitas i dalam nasional, dan $\mathrm{E}=$ Total tenaga kerja di nasional

Untuk menentukan seberapa besar dampak sektor basis terhadap perekonomian regional secara keseluruhan dapat digunakan rumus berikut:

$$
M E=\frac{E \text { total }}{\text { Ebasis }}
$$

dimana ME = Multiplier Effect, $\mathrm{E}$ total = Jumlah tenaga kerja total regional, dan $\mathrm{E}$ basis $=$ Jumlah tenaga kerja di sektor basis

Pembangunan perkebunan kelapa sawit akan memiliki dampak yang cukup luas terhadap perekonomian desa. Dampak tersebut dimulai dari adanya investasi pada perkebunan kelapa sawit baik untuk perluasan areal maupun untuk intensifikasi. Bahwa sejak beberapa tahun belakangan para petani di Provinsi Jambi mulai tertarik untuk perluasan kebun kelapa sawit dan intensifikasi perkebunan kelapa sawit tersebut sehingga berpengaruh 
terhadap perluasan areal dan peningkatan produksi (Dinas Perkebunan Provinsi Jambi, 2012).

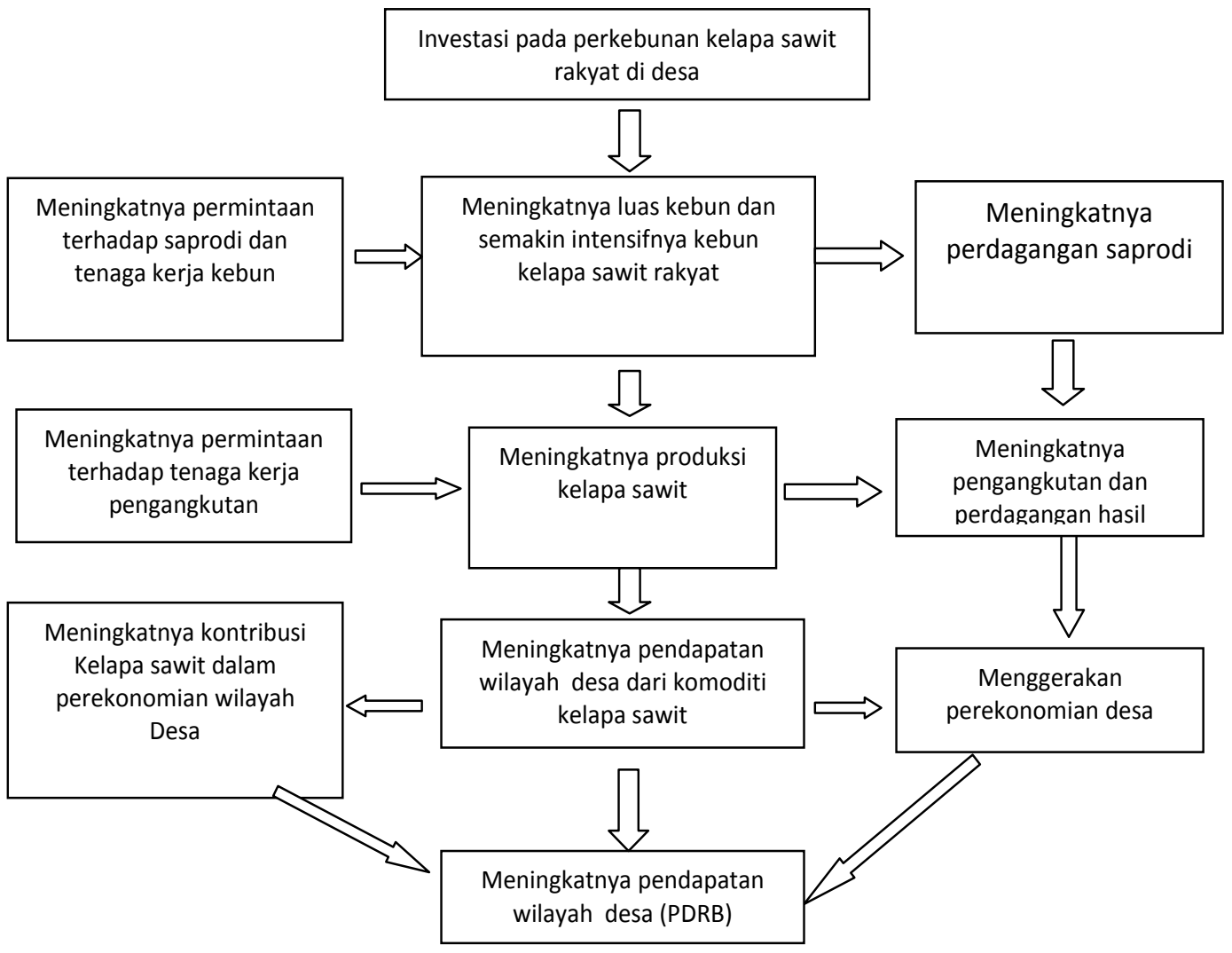

Gambar 1.

Bagan alir dampak perkebunan kelapa sawit rakyat terhadap perekonomian wilayah.

Berdasarkan uraian dalam latar belakang di atas dapat dirumuskan masalah penelitian, yaitu sejauh mana perkembangan kebun kelapa sawit dilihat dari perkembangan luas lahan dan produksi di Provinsi Jambi dan sejauh mana dampak perkembangan kebun kelapa sawit terhadap peningkatan pendapatan wilayah desa di Provinsi Jambi.

\section{METODE PENELITIAN}

Penelitian ini mengambil Provinsi Jambi sebagai lingkup wilayah penelitian dan menjadikan desa sebagai objek utama yang diamati. Dimana sejak beberapa dasa warsa telah berkembang tanaman kelapa sawit hampir di semua kabupaten sehingga layak dianggap sebagai penggerak utama 
perekonomian desa. Penelitian ini dilaksanakan pada Bulan April tahun 2012 sampai dengan Bulan Desember tahun 2012.

Penelitian ini menggunakan pendekatan survei (Kuncoro, 2003). Dimana untuk mengkaji desa sebagai objek penelitian akan dikumpulkan sejumlah variabel yang dianggap merupakan gejala umum yang menggeluti perkembangan desa tersebut di Provinsi Jambi. Untuk mengetahui peranan kelapa sawit dalam peningkatan ekonomi desa digunakan data sekunder dan data primer. Data primer khususnya dikumpulkan dari informan desa terutama untuk menghitung pendapatan wilayah desa dengan pendekatan produksi. Data lain dikumpulkan dari Rumah Tangga desa melalui wawancara dan pengamatan langsung. Pengumpulan data dilakukan dengan bantuan kuestioner.

Metode Pengambilan sampel desa data primer adalah multisteps random sampling (Kuncoro, 2003). Pertama ditetapkan beberapa kabupaten yang akan dijadikan lokasi pengambilan sampel berdasarkan topografi wilayah, yaitu Kabupaten Muaro Jambi dan Kabupaten Merangin. Selanjutnya, ditentukan dua kecamatan di masing-masing kebupaten yang memiliki potensi dalam kelapa sawit. Seterusnya dipilih lima desa dalam setiap kecamatan sehingga diperoleh sebanyak 5 desa secara acak sederhana (Kuncoro, 2003). Untuk Kabupaten Merangin, di Kecamatan Tabir Selatan, yaitu Desa Muaro Delang, Sinar Gading, Sungai Sahut, Bungo Antoi, dan Rantau Jaya sedangkan untuk Kecamatan Pemenang terpilih Desa Pauh Menang, Pematang Kancil, Sialang, Sungai Udang, dan Tanah Abang. Untuk Kabupaten Muaro Jambi, di Kecamatan Sungai Bahar, yaitu Desa Bakti Mulia, Marga, Mekar Sari Makmur, Tanjung Baru, dan Trijaya sedangkan untuk Kecamatan Sekernan terpilih Desa Bukit Baling, Galunggung, Suak Putat, Suko Awin Jaya, dan Tunas Baru.

Data yang sudah terkumpul dianalisa dengan metode statitistik deskriptif dan dan disajikan sesuai jenis data yang tersedia dan tujuan yang hendak dicapai dari penelitian ini (Dayan, 1991).

\section{HASIL DAN PEMBAHASAN}

\section{HASIL}

Perkembangan kebun kelapa sawit dilihat dari luas lahan, Produksi, dan Tenaga Kerja di Provinsi Jambi

Perkebunan kelapa sawit di Provinsi Jambi telah berkembang cukup pesat, baik dilihat dari aspek luas lahan, produksi, produktivitas, maupun dalam menyerap tenaga kerja. Perkembangan dalam luas lahan terjadi melalui pemanfatan lahan untuk penanaman kelapa sawit pada lahan baru, seperti semak belukar dan lahan kebun karet tua. Perkembangan luas tersebut diikuti juga oleh penambahan jumlah tenaga kerja yang sebagian terjadi melalui 
migrasi penduduk dari luar daerah. Perkembangan kebun kelapa sawit dapat dilihat pada tabel berikut.

Tabel 1. Perkembangan Luas Kebun, Produksi, Produktivitas, dan Tenaga Kerja pada Kebun Kelapa Sawit di Provinsi Jambi

\begin{tabular}{lcccccc}
\hline No & Tahun & $\begin{array}{c}\text { Luas kebun } \\
(\mathrm{Ha})\end{array}$ & $\begin{array}{c}\text { Produksi } \\
\text { (Ton) }\end{array}$ & $\begin{array}{c}\text { Produktivitas } \\
\text { Ton/Ha }\end{array}$ & $\begin{array}{l}\text { Tenaga Kerja } \\
\text { (Orang) }\end{array}$ & $\begin{array}{c}\text { TK per Ha } \\
\text { (Orang/Ha) }\end{array}$ \\
\hline 1 & 2002 & 302.152 & 660.320 & 2,185 & 108.775 & 0,3600009 \\
2 & 2003 & 326.889 & 664.164 & 2,032 & 117.680 & 0,3599999 \\
3 & 2004 & 365.304 & 795.848 & 2,179 & 131.509 & 0,3599988 \\
4 & 2005 & 403.467 & 936.595 & 2,321 & 145.248 & 0,3599997 \\
5 & 2006 & 422.888 & 1.018 .788 & 2,409 & 152.240 & 0,3600008 \\
6 & 2007 & 448.899 & 1.150 .355 & 2,563 & 161.604 & 0,3600008 \\
7 & 2008 & 484.137 & 1.203 .433 & 2,486 & 174.289 & 0,3599993 \\
8 & 2009 & 489.384 & 1.265 .789 & 2,586 & 176.178 & 0,3599995 \\
9 & 2010 & 513.959 & 1.392 .293 & 2,709 & 185.025 & 0,3599995 \\
10 & 2011 & 532.293 & 1.426 .081 & 2,679 & 266.147 & 0,5000009 \\
\hline
\end{tabular}

Sumber: Statistik Perkebunan Provinsi Jambi tahun 2012

Dari tabel di atas dapat dijelaskan bahwa luas perkebunan kelapa sawit di Provinsi Jambi meningkat dari 302.152 ha pada tahun 2002 menjadi 532.293 ha pada tahun 2011, atau bertambah hampir dua kali lipat. Di pihak lain terlihat juga bahwa terjadi juga peningkatan dalam hal produksi dan produktivitas bahkan dalam hal ketenagakerjaan. Terjadinya peningkatan dalam produktivitas kelapa sawit menunjukan bahwa telah terjadi juga peningkatan dalam teknologi khususnya penggunaan pupuk anorganik. Dari sisi ketenagakerjaan juga terjadi kenaikan dalam penyerapan tenaga kerja per hektar, dimana pada tahun 2002 penyerapan tenaga kerja per hektar adalah sebesar 0,3600009 orang sedangkan pada tahun 2011 meningkat menjadi 0,5000009 orang per hektar. Hal ini menunjukan bahwa pengelolaan kebun kelapa sawit semakin intensif.

Hasil analisa menunjukan bahwa telah terjadi peningkatan luas lahan rata-rata sebesar 6,924\% per tahun atau bertambah sebesar 20.922 ha per tahun antara tahun 2002 sampai dengan tahun 2011. Terjadi juga peningkatan produksi rata-rata sebesar 10,542\% per tahun atau bertambah sebesar 69.615 Ton per tahun antara tahun yang sama. Disamping itu telah terjadi pula peningkatan penyerapan tenaga kerja sebesar $13,152 \%$ per tahun atau bertambah sekitar 14.307 orang tenaga kerja per tahun antara tahun 2002 sampai dengan tahun 2011. Dalam hal tenaga kerja terjadi juga peningkatan 
penggunaan jumlah tenaga kerja per Ha, yaitu dari 0,36 orang per Ha pada tahun 2002 menjadi 0,50 orang per Ha pada tahun 2011.

Beriringan dengan perkembangan luas lahan kebun kelapa sawit juga akan terjadi perkembangan dalam produksi TBS (Tandan Buah Segar) karena tanaman kelapa sawit akan berproduksi setelah 4 sampai dengan 6 tahun. Seterusnya karena TBS adalah bahan baku dalam pembuatan CPO (Cruid Palm Oil) maka terjadi juga perkembangan dalam produksi CPO. Selanjutnya karena sebagian besar dari CPO akan diekspor maka juga terjadi peningkatan dalam nilai ekspor Provinsi Jambi.

Tabel 2. Perkembangan Tanam Total, Luas Tanaman Telah Menghasilkan (TTM), Produksi, dan Produktivitas Kelapa Sawit di Provinsi Jambi

\begin{tabular}{ccccc}
\hline Tahun & $\begin{array}{c}\text { Luas Total } \\
\text { (Ha) }\end{array}$ & $\begin{array}{c}\text { Luas TTM } \\
\text { (Ha) }\end{array}$ & $\begin{array}{c}\text { Produksi TBS } \\
\text { (Ton) }\end{array}$ & $\begin{array}{c}\text { Produktivitas } \\
\text { (Ton/Ha) }\end{array}$ \\
\hline 2000 & 296.010 & 198.210 & 540.540 & 2,7271 \\
2001 & 301.879 & 210.000 & 578.928 & 2,7568 \\
2002 & 302.152 & 218.310 & 660.320 & 3,0247 \\
2003 & 326.888 & 241.139 & 664.164 & 2,7543 \\
2004 & 365.304 & 267.706 & 795.848 & 2,9728 \\
2005 & 403.467 & 292.314 & 936.595 & 3,2041 \\
2006 & 422.888 & 308.629 & 1.018 .768 & 3,3009 \\
2007 & 448.899 & 338.844 & 1.150 .355 & 3,3949 \\
2008 & 484.137 & 363.869 & 1.203 .433 & 3,3073 \\
2009 & 489.384 & 371.808 & 1.265 .789 & 3,4044 \\
2010 & 513.959 & 402.221 & 1.392 .293 & 3,4615 \\
2011 & 532.293 & 417.304 & 1.426 .081 & 3,4174 \\
\hline
\end{tabular}

Sumber: Statistik Perkebunan Provinsi Jambi 2012

Dari tabel 2 dapat dijelaskan bahwa pada tahun 2000 di Provinsi Jambi terdapat luas kebun kelapa sawit menghasilkan 198.210 ha dan meningkat menjadi 417.304 pada tahun 2011. Demikian juga produksi pada tahun 2000 di Provinsi Jambi ada sebanyak 540.540 Ton dan meningkat menjadi 1.426.081 Ton pada tahun 2011. Dari tabel juga dapat dijelaskan bahwa produktivitas kelapa sawit juga meningkat dari 2,7271 Ton per Ha menjadi 3,4174 Ton per Hektar pada tahun 2011.

\section{Pendapatan Wilayah Desa}

Pendapatan wilayah desa yang dimaksud disini adalah Pendapatan Domestik Regional Bruto (PDRB) desa. Pendapatan ini dihitung dengan 
pendekatan produksi, yaitu dengan menghitung nilai produksi (nilai tambah produksi) dari masing-masing subsektor/sektor yang dihasilkan di wilayah desa yang bersangkutan. Lebih jauh penghitungan ini dimaksudkan untuk mengetahui perubahan perekonomian desa dari masing-masing sektor/sub sektor. Terutama sekali dimaksudkan untuk mengetahui potensi sektor/sub sektor pertanian dan komoditi kelapa sawit itu sendiri.

Tabel 3. Produk Domestik Regional Bruto (PDRB) Rata-rata Desa Sampel menurut Sektor/Sub Sektor/Komoditi Tahun 2011 menurut Harga Berlaku

\begin{tabular}{|c|c|c|}
\hline SEKTOR EKONOMI & PDRB (Rp) & $\begin{array}{l}\text { KONTRIBUSI } \\
\text { SEKTOR }(\%)\end{array}$ \\
\hline 1. Pertanian & 10.395.902.503 & 80,225935 \\
\hline a. Tanaman Bahan Makanan & 265.869 .334 & 2,051733 \\
\hline b. Tanaman Perkebunan & 9.966 .786 .318 & 76,914414 \\
\hline 1) Kelapa Sawit & 5.824 .180 .838 & 44,945627 \\
\hline 2) Karet & 4.140 .594 .805 & 31,953271 \\
\hline 3) Tanaman lain & 2.010 .675 & 0,015517 \\
\hline c. Peternakan dan hasil hasilnya & 103.175 .755 & 0,796215 \\
\hline d. Kehutanan & 0,0 & 0,0 \\
\hline e. Perikanan & 60.071 .097 & 0,463573 \\
\hline 2. Pertambangan dan Penggalian & 57.600 .000 & 0,444503 \\
\hline 3. Industri Pengolahan & 187.195.000 & 1,444597 \\
\hline 4. Listrik, Gas dan Air Bersih & 709.679 .000 & 5,476644 \\
\hline 5. Bangunan & 18.250 .000 & 0,140837 \\
\hline 6. Perdagangan, Hotel dan Restoran & 1.351.000.000 & 10,425765 \\
\hline 7. Pengangkutan dan Komunikasi & 238.455 .000 & 1,840175 \\
\hline 8. Keuangan, Persewaan, dan Jasa Perusah & 200.000 & 0,001543 \\
\hline 9. Jasa-Jasa & 0,0 & 0,0 \\
\hline TOTAL & 12.958.281.503 & 100,00000 \\
\hline
\end{tabular}

Sumber: Hasil olahan data primer (2011)

Dari tabel diatas dapat dijelaskan bahwa rata-rata PDRB desa sampel adalah Rp. 12.958.281.503,- per tahun dengan kontribusi terbesar dari sektor pertanian, yaitu $80,2259 \%$. Diikuti oleh Sektor Perdagangan, Hotel, dan Restoran sebesar Rp. 1.351.000.000,- per tahun atau sekitar 10,4257\% dan Sektor Listrik, Gas, dan Air Bersih sebesar Rp. 709.679.000,- atau kira-kira $5,4766 \%$. Selanjutnya, Sub Sektor Perkebunan memegang peranan penting yang terlihat dari kontribusi sub sektor perkebunan sebesar $76,9144 \%$ dari total PDRB Desa. Dari sub sektor perkebunan itu sendiri terlihat komoditi kelapa sawit memegang posisi dominan, yaitu memberikan kontribusi sebesar 
$44,9456 \%$ dan diikuti oleh komoditi karet dengan kontribusi sebesar 31,9532\% dari total PDRB desa.

Dapat dijelaskan bahwa kegiatan perdagangan yang menonjol di desa adalah perdagangan hasil pertanian dan perdagangan barang-barang kebutuhan harian. Beberapa desa memiliki pedagang hasil pertanian yang dikenal dengan nama tengkulak, baik tengkulak kelapa sawit maupun tengkulak karet. Perdagangan barang-barang konsumsi dilaksanakan oleh warung manisan dan warung kelontong yang kadang-kadang kedua digabung dalam warung yang sama.

\section{Dampak perkebunan kelapa sawit terhadap peningkatan pendapatan wilayah desa di Wilayah Penelitian}

Menurut teori ekonomi basis (Export Base Theory) (Lardaro L., 1993) jika suatu sektor merupakan sektor basis maka sektor tersebut memiliki dampak terhadap pendapatan desa. Untuk itu, bisa dihitung nilai dampaknya dengan rumus "Multiplier Effect" (ME). Untuk mengetahui apakah suatu sektor merupakan sektor basis atau bukan basis digunakan rumus LQ (Location Quotient) dan untuk mengetahui besar dampaknya digunakan rumus ME (Multiplier Effect). Menurut teori ini jika nilai LQ $>1$ maka sektor tersebut adalah sektor basis berarti sektor tersebut memiliki dampak terhadap pendapatan wilayah yang besarnya sama dengan ME. Sebaliknya jika sektor tersebut memiliki nilai LQ $\leq 1$ maka sektor tersebut dianggap bukan sektor basis. Oleh karena itu dianggap tidak memiliki dampak terhadap pendapatan wilayah desa. Untuk menentukan nilai LQ itu maka digunakan rumus dalam Isard, dkk (1998).

Jika dari hasil penelitian diketahui bahwa di desa yang bersangkutan kelapa sawit adalah sektor basis maka dapat pula diketahui bahwa kelapa sawit di desa yang bersangkutan berdampak terhadap pendapatan wilayah desa. Hasil perhitungan LQ untuk desa-desa sampel dengan referensi kelompok desa di kecamatan yang bersangkutan menjelaskan sebagaimana tercantum pada tabel 4.

Dari teori ekonomi basis diketahui bahwa dalam suatu wilayah akan ada satu atau beberapa sektor basis. Dari tabel diatas dapat dijelaskan bahwa di Kecamatan Sungai Bahar terdapat 3 desa yang memiliki sektor basis pada kelapa sawit, Desa Bakti Mulia, Desa Tanjung Baru dan Desa Trijaya. Di Kecamatan Sekernan hanya terdapat satu desa yaitu Desa Suko Awin Jaya, di Kecamatan Tabir Selatan terdapat 4 desa, yaitu Desa Bungo Antoi, Desa Rawa Jaya, Desa Sinar Gading, dan Desa Sungai Sahut. Sedangkan di Kecamatan Pemenang hanya terdapat satu desa, yaitu Desa Pauh Menang. 
Tabel 4. Desa-desa yang komoditi kelapa sawit merupakan sektor Basis dan Tidak Basis Di Wilayah Penelitian tahun 2011

\begin{tabular}{lllll}
\hline NO & NAMA KECAMATAN/DESA & $\begin{array}{c}\text { BASIS/TDK } \\
\text { BASIS }\end{array}$ & LQ & ME \\
\hline & KECAMATAN SUNGAI BAHAR & & & \\
\hline 1 & Bakti Mulia & Basis & 1,055601277 & 1,042628205 \\
2 & Marga & Tidak Basis & 0,970546921 & \\
3 & Mekar Sari Makmur & Tidak basis & 0,962813881 & \\
4 & Tanjung Baru & Basis & 1,000427009 & 1,1001299 \\
5 & Trijaya & Basis & 1,016244334 & 1,083006938
\end{tabular}

\begin{tabular}{lllll}
\hline & KECAMATAN SEKERNAN & & & \\
\hline 6 & Bukit Baling & Tidak Basis & 0,728735834 & \\
7 & Galunggung & Tidak Basis & 0,793728895 & \\
8 & Suak Putat & Tidak Basis & 0,674159876 & \\
9 & Suko Awin Jaya & Basis & 2,080635812 & 1,966414461 \\
10 & Tunas Baru & Tidak Basis & 0,246534466 & \\
& & & & \\
\hline
\end{tabular}

\begin{tabular}{|c|c|c|c|c|}
\hline \multicolumn{5}{|c|}{ KECAMATAN TABIR SELATAN } \\
\hline 11 & Bungo Antoi & Basis & 1,572697191 & \multirow[t]{2}{*}{1,099967371} \\
\hline 12 & Muaro Delang & Tidak Basis & 0,471299358 & \\
\hline 13 & Rawa Jaya & Basis & 1,439528054 & 1,201724127 \\
\hline 14 & Sinar Gading & Basis & 1,501145172 & 1,152397267 \\
\hline \multirow[t]{2}{*}{15} & Sungai Sahut & Basis & 1,477443848 & 1,170884156 \\
\hline & \multicolumn{4}{|c|}{ KECAMATAN PEMENANG } \\
\hline 16 & Pauh Menang & Basis & 1,552797369 & 1,26788357 \\
\hline 17 & Pematang Kancil & Tidak Basis & 0,717493471 & \\
\hline 18 & Sialang & Tidak Basis & 0,851279292 & \\
\hline 19 & Sungai Udang & Tidak Basis & 0,843556577 & \\
\hline 20 & Tanah Abang & Tidak Basis & 0,630357127 & \\
\hline
\end{tabular}

Sumber: Olahan data primer 2011.

Hasil penelitian secara keseluruhan menjelaskan bahwa nilai LQ dari desa-desa sampel berkisar antara 0,246534466 sampai dengan 2,080635812 atau rata-rata sebesar 1,040685128 atau rata-rata lebih besar dari 1 . Untuk itu, secara keseluruhan komoditi kelapa sawit di desa-desa sampel adalah sektor basis dan dianggap memiliki dampak, yaitu sebesar ME (multiplier effect) yang nilainya dapat dicari dengan rumus diatas (Isard dkk, 1998).

118 | Armen Mara dan Yanuar Fitri, Dampak Perkebunnan Sawit Rakyat... 
Hasil perhitungan menunjukan bahwa nilai ME berkisar antara 1,083006938 sampai dengan 1,966414461 atau nilai rata-rata untuk desa sampel adalah 1,231670666. Angka ini menunjukan bahwa jika dilakukan investasi pada komoditi kalapa sawit sebesar Rp. 1,- maka akan berdampak atau mampu meningkatkan pendapatan di wilayah desa sebesar 1,410724452kali. Untuk lebih jelasnya dapat dilihat pda tabel 4 .

\section{PEMBAHASAN}

Undang-undang Nomor 18 tahun 2004 tentang Perkebunan dan Kepmentan No.940/Kpts/OT.210/10/97 tentang Pedoman Kemitraan usaha Pertanian memberikan amanah bahwa arah pembangunan perkebunan adalah meningkatkan kesejahteraan dan kemakmuran petani yang berkeadilan. Pola kemitraan dilaksanakan guna memperlancar jalan menuju kejahteraan petani, khususnya di lokasi yang bersangkutan. Lingkup kerjasama antara kedua belah pihak mencakup kerjasama penyediaan sarana produksi, proses produksi, pengolahan, transportasi, operasional, kepemilikan saham, dan jasa pendukung lainnya.

Hasil penelitian menjelaskan bahwa peranan perkebunan besar kelapa sawit dalam peningkatan ekonomi desa baru sebatas pemasaran TBS ke PKS. Dimana semua petani menjual TBS-nya ke Perusahaan Besar. Namun, perkembangan ekonomi desa akan tersendat karena luas lahan yang bisa dikuasai petani relatif kecil, yaitu 2 ha sampai dengan 5 ha. Untuk itu, kemitraan antara perkebunan rakyat dengan perkebunan besar perlu dilanjutkan ke aspek pemilikan saham di perusahaan perkebunan besar dan bisa bergerak dalam pengolahan hasil, transportasi, operasional dan lainnya sesuai Undang-undang.

Untuk mewujudkan cita-cita di atas diperlukan kebijakan bersama dari pemerintah, yaitu dalam usaha membesarkan koperasi perkebunan rakyat yang sekarang kecil dan lemah menjadi koperasi perkebunan rakyat yang besar dan kuat.

\section{KESIMPULAN DAN SARAN}

Dari hasil penelitian yang telah diuraikan dapat disimpulkan sebagai berikut:

1. Perkebunan kelapa sawit di Provinsi Jambi telah tumbuh cukup pesat, khususnya antara tahun 2002 sampai dengan tahun 2011, luas kebun kelapa sawit tumbuh rata-rata sebesar $6,54 \%$ per tahun. Dari aspek produksi perkebunan kelapa sawit telah tumbuh sebesar 9,11\% 
per tahun dan dari penggunaan tenaga kerja telah tumbuh sebesar $11,02 \%$ per tahun.

2. Pendapatan Domestik Regional Bruto (PDRB) desa yang dihitung dengan pendekatan produksi dan atas dasar harga berlaku tahun 2011 sangat beragam, yaitu berkisar antara Rp. 2.418.250.110,- sampai dengan Rp. 35.322.920.450,- atau rata-rata Rp. 24.682.486.000,- per desa atau rata-rata sebesar Rp. 10.664.964,- per kapita.

3. Dengan menggunakan pendekatan LQ (Location Quotient) perkebunan kelapa sawit dinyatakan sektor basis di lokasi penelitian dengan LQ rata-rata sebear 1,02935, yaitu besar dari 1. Untuk itu kebun kelapa sawit dinyatakan berdampak terhadap PDRB desa yang besarnya sama dengan ME yaitu 1,4107 (rata-rata), artinya jika terjadi peningkatan pendapatan kelapa sawit sebesar Rp.1,- maka akan mampu meningkatkan PDRB desa sebesar 1,4107 kali PDRB kelapa sawit tersebut. Dampak tersebut terjadi terhadap sektor perdagangan, hotel dan restoran, sektor listrik, gas, dan air bersih, sektor pengangkutan dan komunikasi, serta sektor industri pengolahan. berikut:

Berdasarkan kesimpulan penelitian di atas dapat disarankan sebagai

1. Untuk mengetahui PDRB desa yang lebih akurat maka perhitungan PDRB perlu dilakukan juga dengan pendekatan konsumsi yang belum dilakukan dengan penelitian ini.

2. Untuk meningkatkan PDRB desa di Provinsi Jambi maka dapat dilakukan dengan strategi memprioritaskan investasi pada komoditi kelapa sawit rakyat.

\section{UCAPAN TERIMAKASIH}

Penulis mengucapkan terimakasih kepada Direktorat Jenderal Penelitian dan Pengabdian pada Masyarakat Dirjen Dikti Kemdikbud atas dukungan dana penelitian yang diberikan melalui Skim Penelitian Unggulan Perguruan Tinggi Tahun Anggaran 2012. 


\section{DAFTAR PUSTAKA}

Ace Partadiredja. 1983. Perhitungan Pendapatan Nasional (edisi keempat). LP3ES. Jakarta.

Anggiat Heriyanto. 2009. Peranan perkebunan kelapa sawit dalam perekonomian wilayah di Provinsi Jambi. Fakultas Pertanian Universitas Jambi. Jambi.

Anto Dayan. 1991. Pengantar Metoda Statistik (edisi 15), jilid 1 dan 2. LP3ES. Jakarta.

Isard, W, Iwan, J,A, Drennan, P,M, Miller, E,R, Saltzman, S, Thorbecke,E. 1998. Methods of interregional and regional analysis. Ashgate. Singapore.

Mudradjad Kuncoro. 2003. Metode Riset untuk Bisnis dan Ekonomi. Penerbit Erlangga. Jakarta.

Pemerintah Provinsi Jambi, Dinas Perkebunan Provinsi Jambi. 2012. Statistik Perkebunan Provinsi Jambi Tahun 2011. Disbun Provinsi Jambi. Jambi.

Rita Mariati. 2009. Pengaruh Produksi Nasional, Konsumsi, dan Harga Dunia terhadap Ekspor Crude Palm Oil (CPO) di Indonesia. Jurnal Ekonomi Pertanian dan Pembangunan, 6(1): 30-35. Jurusan Sosial Ekonomi Pertanian Universitas Mulawarman. Banjarmasin.

Ropingi dan Yanwar Sudartono. 2008. Pembangunan Wilayah Kecamatan Berbasis Komoditas Pertanian di Kabupaten Gunung Kidul Provinsi Daerah Istimewa Yogyakarta. Jurnal Ilmu ilmu Pertanian, 4(2): Desember 2008. Yogyakarta.

Rozaina Ningsih, Armen Mara, dan Siti hartinah. 2011. Dampak Pemekaran Wilayah terhadap Laju Pertumbuhan Ekonomi di Provinsi Jambi. Jurnal Sosio Ekonomika Bisnis. Fakultas Pertanian Universitas Jambi. Jambi.

Soepadiyo Mangoen Soekarjo dan Haryono Semangun. 2005. Manajemen Agrobisnis Kelapa Sawit. UGM Press. Yogyakarta.

Wayan R, Susila, dan IDM Darma Setiawan. 2007. Peran Industri Berbasis Perkebunan dalam Pertumbuhan Ekonomi dan Pemerataan : Pendekatan Sistem Neraca Sosial Ekonomi. Jurnal Agro Ekonomi. 25(02): Litbang Deptan. Jakarta. 